Ballestero S., A. (2012). Transparency in Triads. PoLAR: Political and Legal Anthropology Review, 35(2), 160-166. doi:10.1111/j.1555-2934.2012.01196.x

\title{
Transparency in Triads
}

Andrea S. Ballestero, Rice University [ORCID: 0000-0001-7692-0514]

What if the more transparency one intends to create, the more obscure things become? What if transparency's literal impossibility were not a conclusion but a premise for how we study political and legal relations? Would this approach shift the traces that we follow in our ethnographic investigations of transparency as a political technology? This Special Issue of PoLAR takes on these questions and brings together four articles that through exciting routes examine transparency as a phenomenon that transcends questions of the visible and the invisible. The authors focus on the instruments of transparency - the circulation of envelopes, the production of numbers about the self, the manufacturing of records, and the formalization of relations - as ways to open up the uses, and abuses, of this ubiquitous form of political sociality. They analyze the means through which transparency is supposedly produced and explore ethnographically some of the legal techniques used for this purpose in India, Costa Rica, and in Congolese Refugee Camps in Tanzania. The authors' attention to instrumentality reveals the misappropriations and reinterpretations of transparency as a project full of ambiguities, ironies, and slippages and also brings forth questions about their intended effects. By asking what transparency projects are intending to effect beyond making the opaque visible, the articles in this collection problematize taken-for-granted ideas about who is observing and who is observed, about the materiality of documents as vessels of knowledge, and, ultimately, about the desirability of transparent arrangements. As a group, the articles turn the dyad transparency/opacity into a triad by incorporating a series of third elements that reveal expected and unexpected bureaucratic, epistemological, and affective connections.

As a political and legal device, transparency technologies are intended to correct the democratic deficits of existing forms of law, bureaucracy, and even subjectivity. Here, transparency is as a form of intervention into a world constituted by relations that can be molded, corrected, and regimented (Bessire 2005; Gaonkar and McCarthy 1994). In existing accounts of transparency, those relations tend to be characterized in three ways. First, there is the idea that mechanisms creating transparency are exemplary neoliberal tools of governance that mostly produce 
individualistic, market friendly, and measurable entities (Shore 2008). Secondly, and intimately related to the first, transparency is characterized as a part of a recently globalized governance ethos that promotes voluntary forms of regulation and formalized types of accountability across radically different geographic contexts (Garsten and Lindh de Montoya 2008:3; von [End Page 160] Benda-Beckman et al. 2009). And finally, analyses of transparency often take conspiracy and secrecy as qualities of contemporary forms of authority, of institutionalized hierarchies, and of sovereign governments that, due to their very nature, are inscribed in modernity's fundamental ideologies of progress and rationality (Sanders and West 2003).

The authors in this collection, however, do not take these ideas for granted. Instead of accepting them as given characteristics of our contemporary contexts, they take on the task of exploring them ethnographically. This methodological move helps to elucidate the ways in which transparency works to create legal and political landscapes that exceed opacity and "neoliberalized" logics. Here, the issue of ethnographic attention to legal instruments and political mechanisms is salient again. Looking at technicalities (Riles 2005; Valverde 2009), techniques (Burchell 1996; Mauss 2006), and technologies (Latour 2004; Parameshwar Gaonkar and Povinelli 2003) complicates stable narratives about opacity and visibility, forcing us to first engage with the slippages, confusions, and translations involved in these projects and then to theorize what they might stand for. As a result, the articles in this collection show us some of the ways in which neoliberal tools of governance can be enrolled to create the developmental state and to constitute political collectives. They show us how international institutions that could be described as conspiratorial organizations are indeed fragile entities that depend on the circulation of open secrets about their own lack of transparency for their efficacy. And they highlight the affective engagements that make our relations with the visible extremely ambivalent and complex.

Parallel to their interest in technique, the authors' concern with opening up the transparency/opacity dyad also speaks to broader questions about the extent to which social commentators and informants share epistemological foundations. I am particularly thinking of the tendency to make the visibility/opacity dyad both the phenomenon to be explained and the basis of explanation. Existing, and by now classic, collections on transparency and accountability (Garsten and Lindh de Montoya 2008; Strathern 2000; West and Sanders 2003) have, in general, assumed that the oscillations between visibility and opacity that transparency mechanisms purport to create can be explained by using those very concepts of visibility and opacity, even if it is to problematize them. That symmetry between phenomena under investigation and theorization seemes problematic because it keeps explanation within the limits of the very ideology of the phenomenon under examination. Yet this symmetry between transparency projects and the analysis of transparency proves difficult to escape, in part because of the embeddedness of our analytic tools in the epistemological traditions of modernity and enlightment from which transparency as a legal and political project emerges. Nevertheless, this collection is an intervention that, without attempting to completely displace opacity and visiblity from our explanatory terms, introduces a series of third elements into that dyad. Those third elements are materiality (Thomson), implementability (Mathur), ethics (Webb), and laughter (Ballestero). In some cases, these third elements are unintended consequences; in others, they are planned and thoroughly calculated. Yet what all of them do is to partially dislocate 
transparency's own ideology by asking us to consider whether and how transparency might be understood beyond the realm of the visible. [End Page 161]

The first article by Nayanika Mathur studies documents and their imbrications in everyday bureaucratic practice. In conversation with a growing literature that has recently focused on the multimodality of documents as social devices (Hetherington 2011; Hull 2008; Riles 2006), this piece traces the implementation of a law to promote rural employment in India. In this case, documents are legitimized in relation to transparency but can be better understood, Mathur suggests, in simultaneous relation with a third element of bureaucratic practice: the notion of implementability.

Yet implementability is not a straightforward aspiration either. It is not limited to the creation of desired effects, in this case the reduction of unemployment, but involves a more immediate administrative concern with the timely and orderly disbursement of funds. Installments, budgets, and receipts all become evidence of the liveliness of the state's activity. This attention to the financial side of state-making adds to an anthropology of finance that has, for the most part, focused on private entities (Ho 2009; Maurer 2005; Riles 2011) and provides important insights into the interplay between record-keeping, document production, and financial management within the state. Mathur's examination of the documentary side of public accounts, fund transfers, and redistributive policies reveals a surprising world of excess. India is thus not a world of financial scarcity, but one in which financial resources are always plentiful, but difficult to mobilize and hard to quantify. When not spent, those resources continue to hover above the reputations of politicians and middle-level bureaucrats. It is at this political juncture of implementability that the "job card" emerges as another physical manifestation of the pay that laborers receive. Conceived as a device to police the lawful contracting of workers, the job card is very quickly included in a documentary economy of access to funds where cards are "rented out, sold, bought, borrowed, and stolen" (178). In this context, paperwork and red tape are rolled out to transform the rights-based approach to development into a "paper-based approach."

In India, mid- and low-level bureaucrats are responsible for producing paper traces; conversely, in the Congolese refugee camps in Tanzania that Marnie Thomson studies, it is not international bureaucrats but individual subjects who have to make themselves transparent. Thomson's article follows the attempts by refugees to activate the international bureaucratic regime by carefully and patiently participating in a generalized documenting frenzy. Refugees are constantly collecting and producing documents about their lives in order to document their own subject position as victims of persecution. Following the circulation of an envelope carefully assembled as evidence of a refugee's life history, Thomson shows the inversion of transparency demands from institutions to outside individuals. Here, the refugee is the one who has to make herself recognizable and traceable in an international bureaucratic structure that allows aid representatives to rely on procedural maneuvers to manage the trauma and urgency that undergird refugee requests for asylum in a third country. Here, bureaucratic institutions escape the obligation to account for their own decisions without actually needing to conceal their lack of transparency in any way.

By taking the above mentioned inversion and its material constitution through envelopes and files as focal points, Thomson finds that it is not corruption that bothers refugees, but the 
patience that is expected from them when years pass by while they [End Page 162] get no information about their cases. In those situations, rejection letters seem to drop from the sky with no clear substantive connections to their writers' rationale, except for their linkages to preceding administrative events (e.g., signatures and stamps) within the file itself. The letters that communicate the United Nations' (UN's) final decisions about refugee requests become pedagogical moments from which applicants draw conclusions. Later, in their appeals or in their advising of other petitioners, applicants adapt their language, the types of stories they tell, and strategize about the type of documents they request from other camp organizations such as clinics.

If, as Thomson shows, pedagogy is central to navigating the international bureaucracy of refugee camps, it is also crucial for the middle-class Indian efforts to implement transparency mechanisms for the urban poor that Martin Webb studies. Focusing on activist work by nongovermental organizations (NGOs), Webb traces how the umbrella of the Right to Information Act became a pedagogical instrument to mold "formalized" relations between poor urban residents and state officials and to replace the informal and "clientelist" relations that have historically allowed some urban groups to access government services. But the participants in the NGOs' pedagogical activities for the Right to Information openly question the desirability of formalized citizen-state relations and, in the process, problematize the very Right to Information that legislation in India, and elsewhere, is squarely designed to promote. At stake here is not only the question of efficacy, that is, can you get information when you request it, but also the desirability of such information in the first place. Why should we want transparency, women's organizations ask, if properly managed clientelist and reciprocal relations with politicians might prove more effective? Pushing not only NGOs but also scholarly assumptions about democratic ideals, Webb's informants ask us to re-examine the grounds on which critiques of transparency are articulated. If from this case we learn that for poor urban residents failure to create transparency might no longer be warranted as a form of critique, on what grounds could we rearticulate our own critical commentary?

Webb examines these pedagogical interventions and their moral undertones as a form of ethical publics (Cohen 2010) intended to regiment interactions between citizens and public officials. Here NGOs work hard, under the guise of transparency, to promote the making of documentary evidence and the creation of a civil society that demands information, both essential ingredients in our contemporary ideas of what liberal democracies are. Suggesting that we have too quickly accepted the desirability of transparency, Webb reminds us of the class-based locations from which those ideas emerge and are transnationally circulated. That middle-class desire to erase information asymmetries and to order relations between hierarchically related actors are also issues that the last article, my own contribution to this issue, explores.

In my article I ask how we can make sense of people's desires to become quantified, and what the role of laughter is in such epistemic projects. How can we rethink presumptions about the supposedly implicit oppressive nature of numbers and quantification tools (Merry 2011; Rotman 1997; Verran 2010)? To answer these questions I document the methods through which a federation of NGOs in Costa Rica translates an ambiguous and indeterminate sense of political agency into numeric indicators. [End Page 163] The categories of indicators they select speak to the different dimensions that an integral depiction of their own work requires if it is to 
adequately convey their understanding of themselves. In this picture of quantification and neoliberal observation of the subject, laughter constantly interrupts the presumed oppressive consequences of numbering and counting. Thus, I ponder, how we might understand this humorous engagement with indicators without presuming that it is a symptom of cynical distancing from the whole auditing exercise. My Costa Rican informants are committed to developing and using this indicator system, not only because of the mere practicalities of accessing financial resources, but also because it provides a vocabulary to finally speak of who they are and what they do (230) with the qualitative properties that they identify with.

Organized around three moments in the process of making a "capacity-building" project transparent, my piece rethinks the assumption that transparency instruments are devised to bridge gaps in information or knowledge between different groups. There are plenty of circumstances, such as this case, in which the utility of indicators lies in their capacity to create a new entity, one that is unspeakable before the quantification exercise is performed. This capability to make entities speakable, paired with the pluralization of centers of regulation and governance across society, requires a rethinking of transparency-creation arrangements in light of their multiple productivities. In this case, laughter became the third element that interrupted discussions about visibility and opacity, gave indicators an emancipatory tone, and allowed NGOs to turn the auditing exercise around for their own purposes.

The four articles in this issue direct our attention to the politics of transparency by exploring the questions that people pose - through transparency mechanisms - to the legal and political arrangements of contemporary national and international governance trends. The articles ask that we consider the politics of form, laughter, ambiguity, and ineffectiveness and their productive implications. By extension, they also take questions about transparency and put them into conversation with long-standing concerns with labor, human rights, refugee migration, and citizen-state relations. Methodologically, one of the ways in which this is accomplished is by moving the commentator's own gaze around and across institutional, organizational, class, and national boundaries, and by encouraging us to consider the polyvalence and multi-locality of the tools through which the politics of transparency are produced and navigated.

But these are not arguments about world systems or localization of globalized forces. The articles exemplify the "multisitedness" of phenomena (Marcus 1995) without falling prey to thin interpretations of the multisited that reduce it to geographic forms of transnationalism. Furthermore, the articles do not provide purified or predictable accounts of how transparency works and what it attempts, instead, they stay close to the slippages, contradictions, and sublimations that are at stake in the making of this modern "political panacea" (Garsten and Lindh de Montoya 2008:1). Transparency is examined across and through sites of politics and the law in order to keep an openness towards its untimely forms (Grosz 2004). I do hope that you enjoy this Special Issue and want to thank the editors of PoLAR, John Conley and Justin Richland, for their [End Page 164] support. I also want to recognize especially the conversations and ideas shared with Amy Levine, Gemma John, Leticia Barrera, Jason Cross, Robert Werth, and Ilana Gershon, all of which gave shape and impetus to this issue. And finally, I thank Kregg Hetherington for generously agreeing to write an afterword that provides another take on the intellectual work that this collection does and the possibilities that it points to. [End Page 165] 


\section{References Cited}

Bessire, Dominique 2005 Transparency: a two way mirror? International Journal of Social Economics 32(2):424-438.

Burchell, Graham 1996 Liberal Government and Techniques of the Self. Chicago: University of Chicago Press.

Cohen, Lawrence 2010 Ethical Publicity: On Transplant Victims Wounded Communities and the Moral Demands of Dreaming. In Ethical Life in South Asia. A. Pandian, and D. Ali, eds. Pp. 253-274. Bloomington: Indiana University Press.

Gaonkar, Dilip Parameshwar, and Robert J. McCarthy, Jr. 1994 Panopticism and Publicity: Bentham's Quest for Transparency. Public Culture 6(3):547-575.

Garsten, Christina, and Monica Lindh de Montoya 2008 Transparency in a New Global Order: Unveiling Organizational Visions. Cheltenham, UK: Edward Elgar.

Grosz, Elizabeth 2004 The Nick of Time: Politics, Evolution, and the Untimely. Durham: Duke University Press.

Hetherington, Kregg 2011 Guerrilla Auditors: The Politics of Transparency in Neoliberal Paraguay. Durham: Duke University Press.

Ho, Karen 2009 Liquidated: An Ethnography of Wall Street. Durham: Duke University Press.

Hull, Matthew S. 2008 Ruled by Records: The Expropriation of Land and the Misappropriation of Lists in Islamabad. American Ethnologist 35(4):501-518.

Latour, Bruno 2004 Scientific Objects and Legal Objectivity. In Law, Anthropology, and the Constitution of the Social: Making Persons and Things. A. Pottage and M. Mundy, eds. Cambridge: Cambridge University Press.

Marcus, George E. 1995 Ethnography in/of the World System: The Emergence of Multi-Sited Ethnography. Annual Review of Anthropology 24:95-117.

Maurer, Bill 2005 Mutual Life Limited: Islamic Banking, Alternative Currencies, Lateral Reason. Princeton: Princeton University Press.

Mauss, Marcel 2006 Techniques of the body. In Marcel Mauss: Techniques, Technology, and Civilization. N. Schlanger, ed. Pp. 77-95. New York: Durkheim Press.

Merry, Sally Engle 2011 Measuring the World: Indicators, Human Rights, and Global Governance: with CA comment by John M. Conley. Current Anthropology 52(S3):S83-S95. 
Parameshwar Gaonkar, Dilip, and Elizabeth A. Povinelli 2003 Technologies of Public Forms: Circulation, Transfiguration, Recognition. Public Culture 15(3):385-397.

Riles, Annelise 2005 New Agenda for the Cultural Study of Law: Taking on the Technicalities. Buffalo Law Review 53:973-1034.

Riles, Annelise, ed. 2006 Documents: Artifacts of Modern Knowledge. Ann Arbor: University of Michigan Press.

Riles, Annelise 2011 Collateral Knowledge: Legal Reasoning in the Global Financial Markets. Chicago: Chicago University Press.

Rotman, Brian 1997 The Truth About Counting. The Sciences November/December:34-39.

Sanders, Todd, and Harry West, eds. 2003 Transparency and Conspiracy: Ethnographies of Suspicion in the New World Order. Durham: Duke University Press.

Shore, Cris 2008 Audit Culture and Illiberal Governance: Universities and the Politics of Accountability. Anthropological Theory 8(3):278-298.

Strathern, Marilyn 2000 Audit Cultures: Anthropological Studies in Accountability, Ethics, and the Academy. London: Routledge.

Valverde, Mariana 2009 Jurisdiction and Scale: Legal 'Technicalities' as Resources for Theory. Social and Legal Studies 18(2):139-157.

Verran, Helen 2010 Number as an Inventive Frontier in Knowing and Working Australia's Water Resources. Anthropological Theory 10(1-2):171-178.

von Benda-Beckman, Franz, Keebet von Benda-Beckman, and Julia Eckert, eds. 2009 Rules of Law and Laws of Ruling: On the Governance of Law. Burlington: Ashgate.

West, Harry G., and Todd Sanders, eds. 2003 Transparency and Conspiracy. Durham: Duke University Press. 